\section{Effect of maxillomandibular fixation on condylar growth in juvenile Macaca mulatta: a cephalometric and histologic study}

Isacsson G, Carlson DS, McNamara JA Jr, Isberg AM: Effect of maxillomandibular fixation on condylar growth in juvenile Macaca mulatta: a cephalometric and histologic study. Scand J Dent Res 1993; 101: 103-9. (C) Munksgaard 1993

The effect of maxillomandibular fixation on the growth of the mandibular condyle was studied in eight control and eight experimental male juvenile monkeys. All animals had metallic implants placed throughout the craniofacial complex in order to facilitate cephalometric analysis of growth-related changes in the maxillomandibular complex during jaw immobilization. Every 3, 6, 12, and $24 \mathrm{wk}$ after insertion of the appliance two experimental animals were killed for histologic analysis. Cephalometric analysis indicated no major deviation from normal maxillary or mandibular growth in the experimental animals. The condylar growth in the experimental animals was comparable with that of the controls. Histologic analysis indicated that the articular connective tissue in experimental joints remained the same thickness as in the controls. On the postero-superior aspect of the condyle, the thickness of the prechondroblasticchondroblastic cell layer was reduced by $70-80 \%$ in the experimental animals. On the posterior aspect this cell layer was not visible after 12 wk of fixation, but was replaced by a periosteum-like, cell-rich tissue which appeared to be active in appositional formation of cancellous bone. These results indicate that long-term maxillomandibular fixation does not cause major alterations in the growth of condyle or the entire mandible despite a profound decrease of the prechondroblastic-chondroblastic cell layer in the postero-superior and posterior regions of the condyle. The growth is probably due to a compensatory appositional bone formation along the surface of the condyle. It is also concluded that jaw mobility is not a prerequisite for normal maxillary or mandibular growth.
Göran Isacsson ${ }^{1}$, David S. Carlson ${ }^{2}$, James A. McNamara, Jr. ${ }^{2}$ and Annika M. Isberg ${ }^{3}$

'Orofacial Pain Clinic, Postgraduate Dental Education Center, Örebro County Council, Örebro, Sweden, ${ }^{2}$ Department of Orthodontics and Pediatric Dentistry and the Center for Human Growth and Development, University of Michigan, Ann Arbor, USA, ${ }^{3}$ Department of Oral Radiology, Karolinska Institute, Stockholm, Sweden

Key words: condyle; immobilization of jaw; mandibular growth; monkey; temporomandibular joint

Göran Isacsson, Postgraduate Dental Education Center, Örebro County Council, P.O. Box 1126, Örebro 70111, Sweden

Accepted for publication 16 May 1992
Several studies document normal growth and development of the craniofacial complex in the rhesus monkey $(1,2)$ with particular reference to the maxillary complex (3) and the mandible $(4,5)$. The normal histology and postnatal growth of the temporomandibular joint (TMJ) have also been described in detail (6-10). These investigations have shown that the thickness of the prechondroblastic-chondroblastic cell layer (i.e. growth cartilage layer) of the mandibular condyle increases dramatically from the neonatal through the juvenile age groups and decreases gradually through the adult group (11).

Immobilization of the mandible of young rhesus monkeys results in impaired bone mineralization and thinning of condylar cartilage (12). Thus, some studies indicate that immobilization of the mandible may lead to impaired mandibular growth. However, the effect of immobilization on the mandibular growth has not been fully documented.

The aim of this investigation was to study the effect of absence of jaw mobility on the growth of the mandibular condyle.

\section{Material and methods}

Animal model - Sixteen male juvenile rhesus monkeys (Macaca mulatta), eight controls and eight experimentals, were used in this study. Control animals were the same as those used in previous 
cephalometric (5) and histologic studies (11) of normal mandibular and condylar growth in the rhesus monkey. Experimental animals were used for the purpose of this study alone.

Dental indication of the juvenile stage of maturational development in rhesus monkeys, chronologically between the ages of 18 and 30 months, is a fully erupted dentition and erupted permanent first molars $(11,13)$. For this study, in addition to possessing these dental criteria, all control and experimental animals were judged to be between the ages of 18 and 24 months. None were less than 18 months of age at the start of the study, and none older than 24 months at its completion. This is significant in terms of the control data for the histologic analysis, as it indicates that all animals were within the juvenile stage of development for the duration of the study. Thus, it was possible to sample the control animals at a single time interval to obtain comparable measurements of each of the histologic variables (11).

Fixation appliance - The appliance and fixation protocol used in this study, which was designed specifically for use in research involving orthognathic surgery in primates (14), provides for complete maxillomandibular fixation with minimal change in vertical dimension. Three to $5 \mathrm{wk}$ before the start of the experiment, the maxillary and mandibular central incisors were extracted in the experiment animals after sedation with ketamine$\mathrm{HCl}$ (i.m. $7-15 \mathrm{mg} / \mathrm{kg}$ ) to facilitate proper feeding during maxillomandibular fixation. Cast ticonium splints were fabricated from alginate impressions taken of maxilla and mandible on each experimental animal. The splints were designed to cover the buccal and the lingual surfaces of the dentition, leaving the occlusal surface free. The splints were cemented to the dentition and were then fastened together by steel ligature wires.

Cephalometric analysis - Each animal was prepared for serial cephalometric analysis before the beginning of the experiment. Tantalum implants were placed into various regions of the craniofacial complex according to standard protocols: four to six implants were placed in the mandible (5), five in the maxilla, three in the midline of the frontal bone, and four to six in the cranial base via an intraoral approach (3). The implants made it possible to monitor growth changes within each craniofacial region and between regions. Serial cephalograms were taken by means of a primate headholder specifically designed for longitudinal studies on monkeys (10).

Cephalograms of the experimental animals were taken immediately before and after the onset of maxillomandibular fixation and at intervals of 3 , 6,12 , and $24 \mathrm{wk}$.
Growth changes in the mandible were analyzed according to the procedures described by MCNAMARA et al. $(3,5)$. Briefly, the outlines of the cranial implants and of the inferior portion of the endocranial surface of the orbital roof were recorded on the initial cephalogram. A reference line was drawn along the functional occlusal plane, establishing the horizontal orientation for the measurements on each animal. Cephalometric changes within the maxillary complex were determined by superimposing successive tracings and measuring the displacement of implants above the first molar region and between the central and lateral incisors in the premaxilla. The growth of the mandible was determined by superimposing the mandibular implants and measuring the horizontal and vertical changes in the region of the mandibular ramus and condyle.

Histologic analysis - Both experimental and control monkeys were killed by overdoses of pentobarbital sodium i.v. Two experimental animals were killed at intervals of $3,6,12$, and $24 \mathrm{wk}$ of maxillomandibular fixation. Control animals were killed 24 wk after the start of the experiment.

Immediately after the lethal injection, the thorax was opened and a catheter was placed in the left ventricle of the heart. Physiologic saline was perfused through the body, followed by a $5 \%$ neutral buffered formaldehyde solution. The left and right TMJs were removed en bloc and kept in additional fixation solution for $1 \mathrm{wk}$ before demineralization in $40 \%$ EDTA at $37^{\circ} \mathrm{C}$. After adequate demineralization, the specimens were routinely processed and embedded in paraffinwax. Sagittal sections were collected from throughout the joint, stained with hematoxylineosin, and examined under a light microscope. A representative section from the region corresponding to the center of the condyle in each joint was selected for measurement by an image analysis system (BIOQUANT) interfaced with a Leitz microscope (magnification $\times 483$ ).

The thickness of the articular connective tissue and the prechondroblastic-chondroblastic zones of the temporal bone was measured at the most inferior part of the eminence and in the fossa according to the methods of Hinton \& CARLSON (15). The corresponding condylar structures were measured on the superior, postero-superior, and posterior aspects (11). No attempt was made to delineate the prechondroblastic zone from the chondroblastic zone, since the gradual nature of their transformation made it difficult to identify a single boundary between these cell layers. The thickness of the layers was measured perpendicular to the articular surface. 


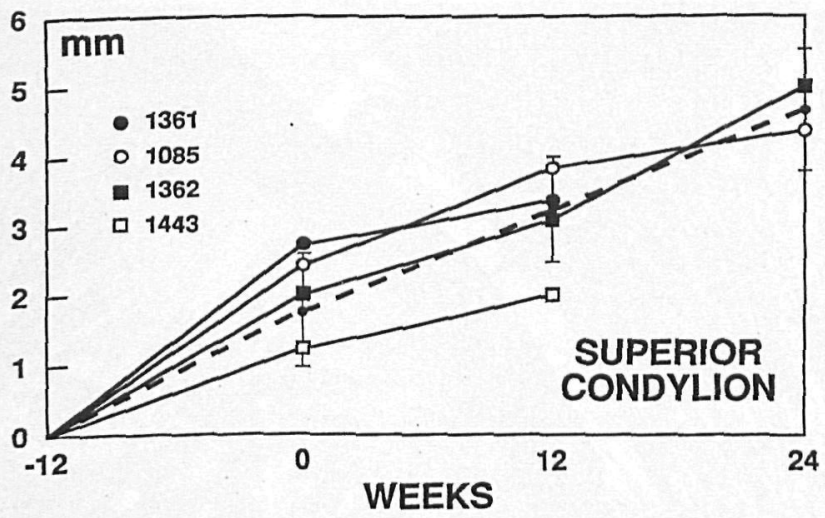

Fig. 1. Graph indicating superior growth of mandibular condyle 12 wk before and up to $24 \mathrm{wk}$ after maxillomandibular fixation. Control monkeys $(n=8)$ are indicated by dashes line (---), with bars indicating one standard deviation. Experimental animals with at least 12 wk of data $(n=4)$ are indicated separately.

\section{Results}

All animals tolerated the intermaxillary fixation appliance well and had little difficulty in maintaining and gaining weight.

\section{Cephalometric evaluation}

Although every attempt was made to maintain the condyle in its normal anatomical position in the glenoid fossa, a comparison of lateral head films taken before and immediately after cementation of the appliance indicated that the position of the condyle within the fossa was displaced approximately 2-3 $\mathrm{mm}$ vertically. The condyles of the experimental animals continued to grow normally during the experimental period, and exhibited no differences from controls (Figs. 1 and 2).

Mandibular growth - During the pre-experimental period, mandibular growth in the experimental animals was equal to that of the controls. Growth of the condyle occurred in an upward and backward direction, and the ramus was relocated posteriorly. The dentition migrated mesially and superiorly.

Maxillary growth - There was some alteration in the amount and direction of maxillary growth because of the placement of the fixation appliance. The normal downward and forward displacement of the maxillary and premaxillary implants was redirected in an upward and slightly forward direction. Because the maxillary and mandibular dental arches were fixed together, the movement of the implants in the mandible was virtually the same as in the maxilla.

\section{Histologic evaluation}

Histomorphology of the condyle - The thickness of the condylar prechondroblastic-chondroblastic cell

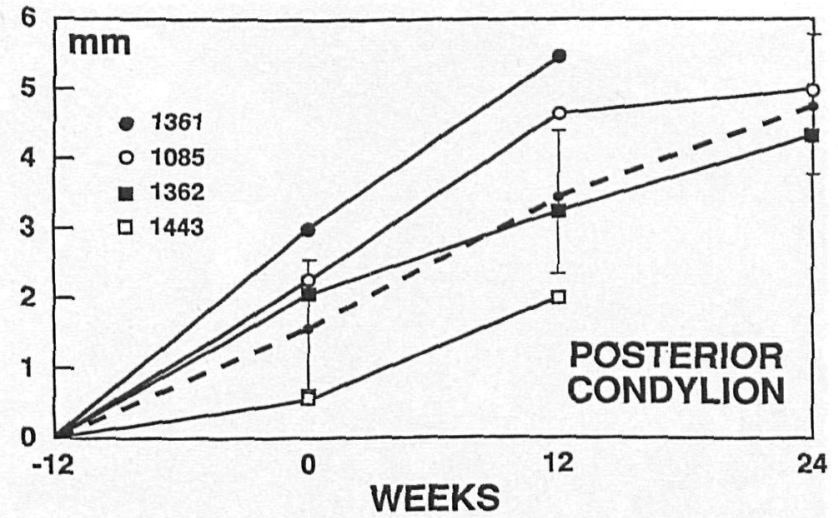

Fig. 2. Graph indicating posterior growth of mandibular condyle 12 wk before and up to 24 wk after maxillomandibular fixation. Control monkeys $(n=8)$ are indicated by dashed line $(---)$, with bars indicating one standard deviation. Experimental animals with at least 12 wk of data $(n=4)$ are indicated separately.

layers among control and experimental animals is illustrated in Table 1. The mean thickness of the superior condylar prechondroblastic-chondroblastic cell layer of the controls was $208 \mu \mathrm{m}$ (SD 55), which was the same magnitude for the experimentals throughout the experimental period. On the postero-superior aspect of the condyle, the thickness of the prechondroblastic-chondroblastic cell layer was reduced among the experimentals, as compared with the controls. This feature became accentuated with time, and after $24 \mathrm{wk}$ of fixation, the thickness was only 56 and $131 \mu \mathrm{m}$, as compared with the mean value of $387 \mu \mathrm{m}$ for the controls. The posterior condylar prechondroblastic-chondroblastic cell layer showed the most dramatic response to the maxillomandibular fixation; the cartilage in this region of the condyle disappeared completely after $12 \mathrm{wk}$. In all experimental animals, only a cap of cartilage was seen on the condyle after $12 \mathrm{wk}$ of fixation. Histologic illustrations are shown in Figs. 3-9. On the posterior and postero-superior aspect of the condyle at the site of

Table 1

Thickness of condylar prechondroblastic-chondroblastic cell layer

\begin{tabular}{rrrr}
\hline & \multicolumn{3}{c}{ Prechondroblastic-chondroblastic layer in $\mu \mathrm{m}$} \\
\cline { 2 - 4 } & Superior & Postero-superior & Posterior \\
\hline Controls & 208 (SD 55) & 387 (SD 124) & 334 (SD 132) \\
Fixation & & & \\
$3 \mathrm{wk}$ & 139 & 121 & 161 \\
$3 \mathrm{wk}$ & 210 & 206 & 133 \\
$6 \mathrm{wk}$ & 68 & 160 & 138 \\
$6 \mathrm{wk}$ & 187 & 187 & 38 \\
$12 \mathrm{wk}$ & 176 & 93 & 0 \\
$12 \mathrm{wk}$ & 194 & 171 & 0 \\
$24 \mathrm{wk}$ & 256 & 56 & 0 \\
$24 \mathrm{wk}$ & 155 & 131 & 0 \\
\hline
\end{tabular}



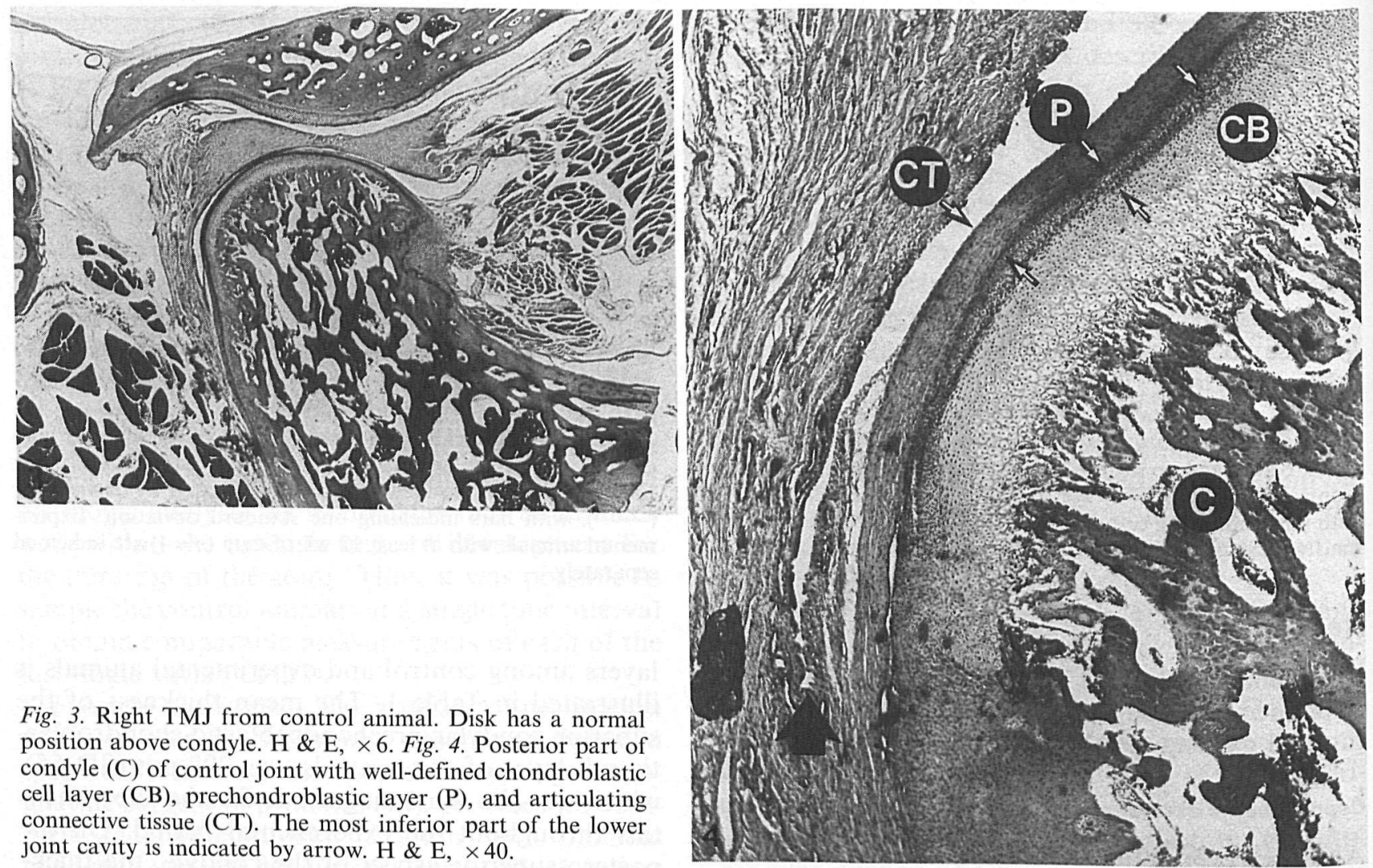

Fig. 3. Right TMJ from control animal. Disk has a normal position above condyle. H \& E, $\times 6$. Fig. 4. Posterior part of condyle $(\mathrm{C})$ of control joint with well-defined chondroblastic cell layer $(\mathrm{CB})$, prechondroblastic layer $(\mathrm{P})$, and articulating connective tissue (CT). The most inferior part of the lower joint cavity is indicated by arrow. $\mathrm{H} \& \mathrm{E}, \times 40$.

the previous prechondroblastic-chondroblastic cell layer, a periosteum-like, cell-rich tissue developed. In this region, appositional bone formation appeared to form cancellous bone which, in the animals killed at $24 \mathrm{wk}$, showed thick trabeculae. One joint in an experimental animal killed after $24 \mathrm{wk}$ of fixation showed localized areas of atrophy of the chondroblastic cell layer (Fig. 9).The condylar articulating connective tissue of the controls had a thickness of $72 \mu \mathrm{m}$ (SD 33) on the superior aspect and $100 \mu \mathrm{m}$ (SD 45) and $118 \mu \mathrm{m}$ (SD 34) on their postero-superior and posterior aspects, respectively. In the experimental animals, the connective tissue had a thickness within the same range as in the controls. On the posterior aspect of the condyle, the connective tissue extended inferiorly to a level corresponding to the controls despite the loss of the growth cartilage.

Histomorphology of the temporal bone - The temporal prechondroblastic-chondroblastic cell layer of the controls had a thickness of $61 \mu \mathrm{m}$ (SD 88) in the fossa and $125 \mu \mathrm{m}$ (SD 54) on the eminence. In the experimental animals the prechondroblasticchondroblastic cell layer progressively decreased in thickness during fixation, so that after $12 \mathrm{wk}$ the layer was absent both in the fossa and on the eminence. One exception was a 12-wk animal who had a $20-\mu \mathrm{m}$-thick prechondroblastic-chondroblastic cell layer on the eminence. Among the controls,

the articulating connective tissue of the temporal bone component had a thickness of $116 \mu \mathrm{m}$ (SD 61) and $105 \mu \mathrm{m}$ (SD 34) in the fossa and on the eminence, respectively. The experimental animals had a thickness of the temporal articulating connective tissue which was equivalent to that of the controls.

No changes of the disk morphology could be seen in any joint.

\section{Discussion}

This study indicates that condylar growth and remodeling remains within normal ranges despite lack of mandibular function. We also found that absence of jaw mobility changed the condylar prechondroblastic-chondroblastic cell layers to a periosteum-like tissue in the areas least likely to become loaded after the jaw fixation, i.e. the posterior and postero-superior parts of the condyle. In the superior part of the condyle, which was the only part that could take up load after the fixation, the prechondroblastic-chondroblastic cell layer remained. It is reasonable to assume, therefore, that the presence of condylar cartilage is associated with function and/or load. We can also conclude that the prechondroblastic-chondroblastic cell layer is not a prerequisite for condylar growth, as we registered normal growth of the condyle without the 


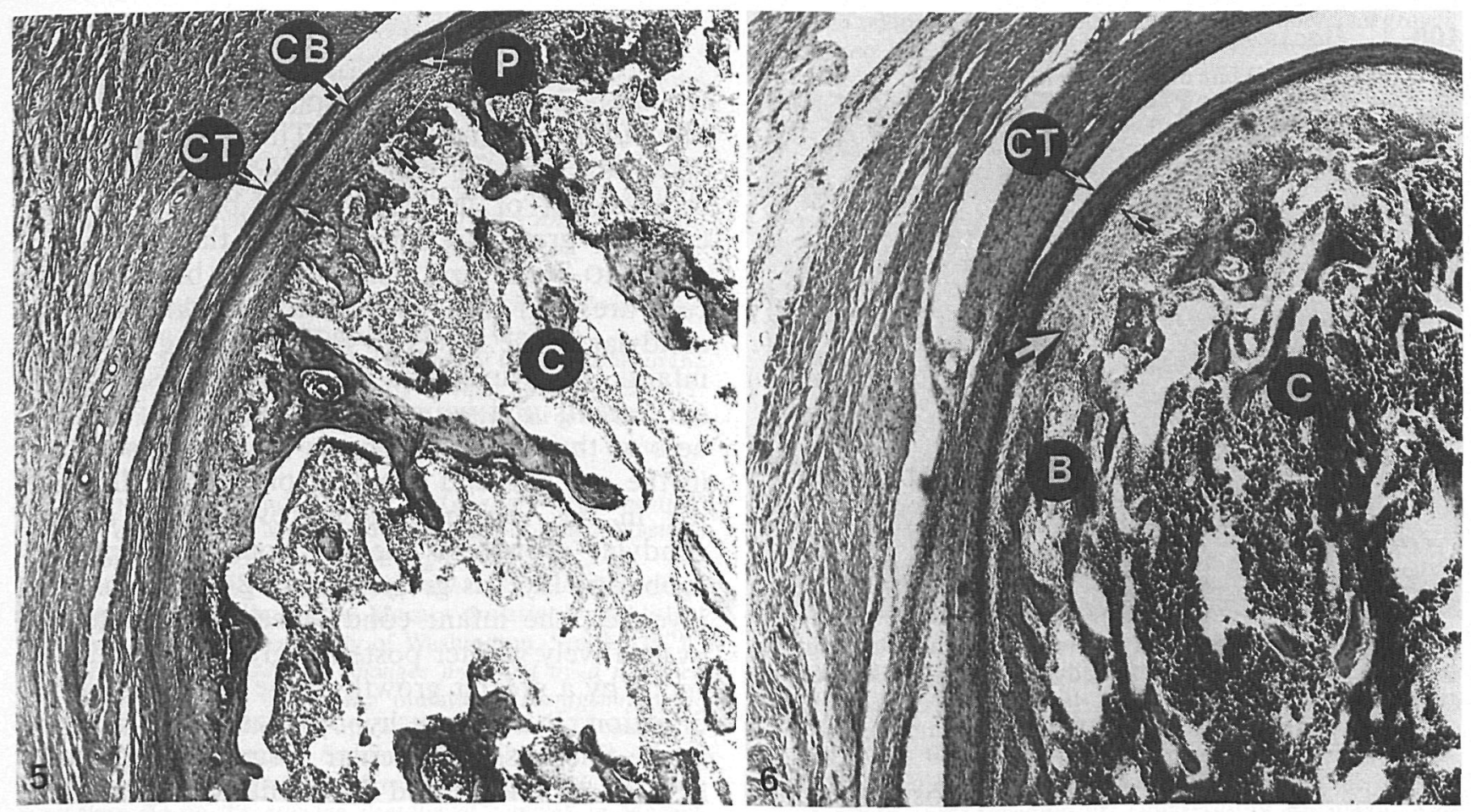

Fig. 5. Posterior part of condyle (C) after 3 wk of intermaxillary fixation. Chondroblastic cell layer (CB) is considerably reduced while thickness of articulating connective tissue layer (CT) remains intact. Prechondroblastic cell layer (P) is atrophic. H \& E, $\times 40$. Fig. 6. Right TMJ after 6 wk of intermaxillary fixation. Posterior aspect of condyle (C) shows no chondroblastic zone while zone of articulating connective tissue (CT) has normal thickness. Membraneous bone formation (B) is seen in area where chondroblastic zone normally appears. Arrow indicates most inferior part of chondroblastic cell layer. H \& E, $\times 40$.
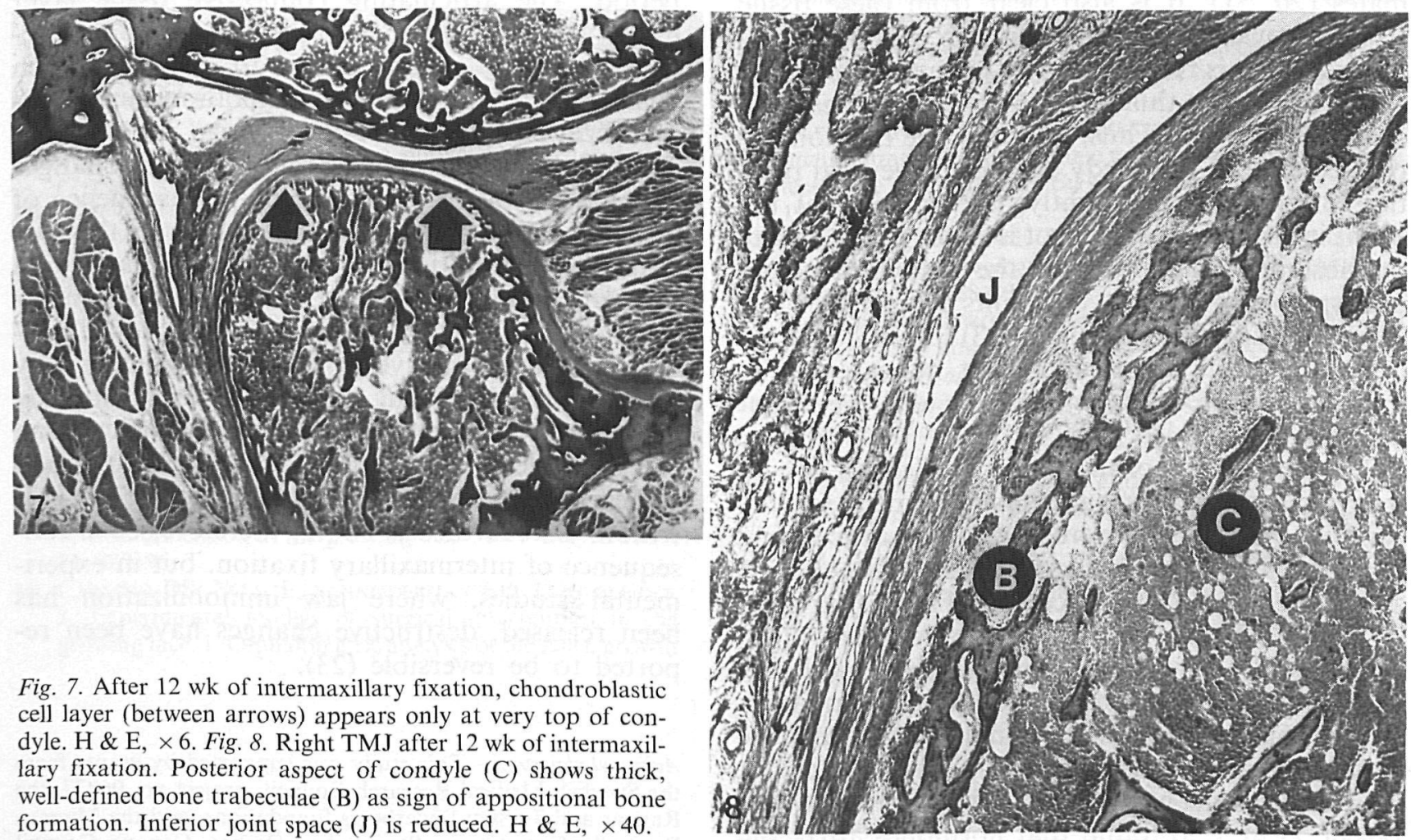

Fig. 7. After 12 wk of intermaxillary fixation, chondroblastic cell layer (between arrows) appears only at very top of condyle. H \& E, $\times 6$. Fig. 8. Right TMJ after 12 wk of intermaxillary fixation. Posterior aspect of condyle (C) shows thick, well-defined bone trabeculae (B) as sign of appositional bone formation. Inferior joint space $(J)$ is reduced. $H \& E, \times 40$. 


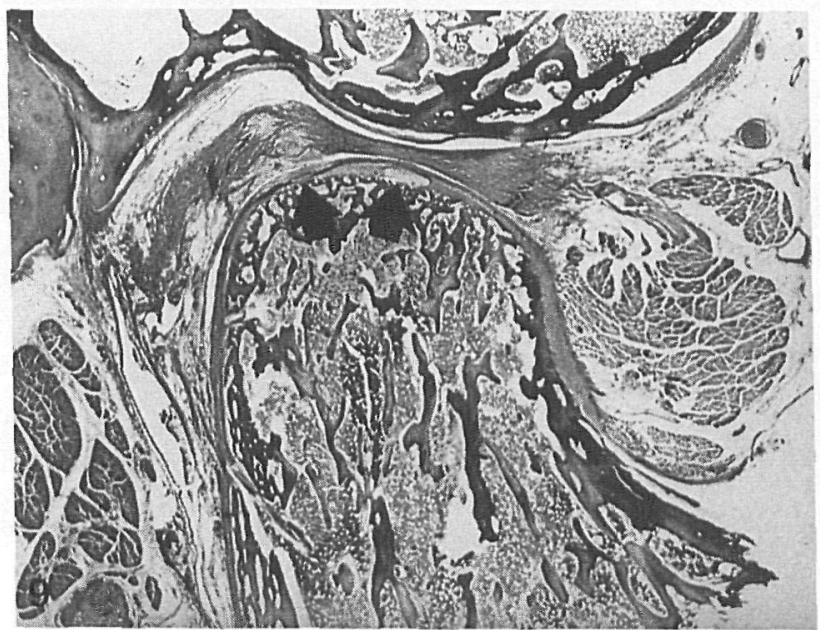

Fig. 9. Right TMJ after 24 wk of intermaxillary fixation. Chondroblastic cell layer at top of condyle shows signs of atrophy (arrows). $\mathrm{H} \& \mathrm{E}, \times 6$.

presence of these cell layers. The posterior and postero-superior condylar growth, which is the main growth direction (16), was found to be regulated through an appositional bone formation.

Substantive increase in the vertical dimension of the growing face produced by cemented cast bite splints has been shown to be associated with significant changes in the growth of the maxillary complex (17-19) and the mandible of nonhuman primates $(20,21)$. It is also clear from these tissue studies, however, that the change in maxillomandibular growth is related directly to the height of the splint (17); the thinner the splint, the less the change in growth. Thus, although the fixation appliance used in this study altered the vertical position of the condyle slightly, the presence of the splint itself was probably not a factor in producing the observed results. Indeed, the condylar changes in response to the use of splints reported in our work (22) and that of others (23) indicate just the opposite effect, i.e. a significant increase in the thickness of the condylar cartilage with the use of the bite splint.

The mandible normally grows through an intramembraneous bone formation, except for the condyle, which is covered with an articulating cartilage. The mandibular periostal cells continue as the prechondroblastic cell layer in the cartilage of the TMJ (for references, see MOYERs (24)). Endochondral growth of the condyle is probably required because appositional bone formation cannot tolerate load. The condylar TMJ cartilage is a secondary cartilage and has therefore a limited intrinsic growth potential. However, PETROVIC et al. (25) found that hormones affect the growth of the condylar cartilage. Experimental studies have shown that condyles detached from the mandible (26) or transplanted with adjacent bone (27) continue to grow. This supports the assumption that the condyle has a growth that is independent of the mandibular body. However, condylar growth is dependent on the presence of adjacent bone, and for that the bone-forming cells are vital (28). The relative thickness of the condylar tissue layers is similar among neonates, infants, and juveniles, and decreases slightly in adolescents and young adults. The relative thickness of the articular tissue is greatest posteriorily in the neonate and becomes proportionally thinner in this region during growth. The rate of condylar growth in the prechondroblastic-chondroblastic layer is greatest among the infants and juveniles, the infant condyle being characterized by relatively greater posterior growth, and the juvenile by a greater growth in the postero-superior direction. It has been hypothesized that variation in the thickness of articular tissue is due primarily to morphologic and functional changes in the TMJ during growth (11), a hypothesis which is supported by our study.

Immobilization of the TMJ does not cause major articular surface changes $(29,30)$; i.e., the articulating connective tissue layer remains intact. This feature was confirmed by our study, in which that tissue structure remained with the same thickness throughout the immobilization period. The articulating connective tissue layer has a very low metabolic activity (31) and therefore probably reacts slowly to stimuli, which could be a reason for its nonalteration during immobilization of jaws. The cartilage of both the TMJ and the knee joint rapidly display changes as an effect of immobilization. A consequence of immobilization is decreased thickness of the cartilage and alterations of the glycosaminoglycan content, changes consistent with those seen in osteoarthrosis (32-34). In our series of growing individuals, degenerative changes were seen in only one animal which had localized areas of atrophy of the superior condylar cartilage. Articulating cartilage lacks a nutritional supply from blood vessels, and synovial fluid is required for the nutrition. Osteoarthrosis could, therefore, be a consequence of intermaxillary fixation, but in experimental studies, where jaw immobilization has been released, destructive changes have been reported to be reversible (23).

Acknowledgments - This study was supported by grants from the Swedish Medical Research Council, project no. 06877, the Ragnar and Torsten Söderbergs foundations, and the Magnus Bergvalls Foundation, Stockholm, Örebro County Council Research Foundation, Sweden, and by NIH-NIDR grant DE03610. 


\section{References}

1. Duterloo HS, Enlow DH. A comparative study of cranial growth in Homo and Macaca. Am J Anat 1970; 127: 357-68.

2. Elgoyhen JC, Riolo ML, Graber LW, Moyers Re, McNAmara JA JR. Craniofacial growth in juvenile Macaca mulatta: a cephalometric study. Am J Phys Anthropol 1972; 36: 369-76.

3. MCNamara JA JR, Riolo ML, Enlow DH. Growth of the maxillary complex in the rhesus monkey (Macaca mulatta). Am J Phys Anthropol 1976; 44: 15-26.

4. TuRPIN DL. Growth and remodelling of the mandible in the Macaca mulatta monkey. Am J Orthod 1968; 54: 251-71.

5. MCNAmara JA JR, Graber LW. Mandibular growth in the rhesus monkey (Macaca mulatta). Am J Phys Anthropol 1975; 42: 15-24.

6. ZIELINSKi DE. A study of the normal anatomy of the masticatory apparatus of Macaca mulatta. Unpublished Master's Thesis, Loyola University, Chicago, 1955.

7. ZIMMERMANN HI. The normal growth and remodelling of the temporomandibular joint of Macaca mulatta. Unpublished Master's Thesis, University of Washington, Seattle, 1971.

8. Cutler BS. Dentofacial changes produced by a modified Milwaukee brace in Macaca mulatta: a roentgenographic and histological study. Unpublished Master's Thesis, University of Washington, Seattle, 1968.

9. NoRWICH KW. The effect of reciprocal intermaxillary forces (class II) on the growing dentofacial complex in Macaca mulatta. Unpublished Master's Thesis, University of Washington, Seattle, 1969.

10. MCNAmARA JA JR. Neuromuscular and skeletal adaptations to altered orofacial function. Monograph \#1, Craniofacial growth series, Center for Human Growth and Development, University of Michigan, Ann Arbor, 1972.

11. Carlson DS, McNamara JA JR, Jaul DH. Histological analysis of the growth of the mandibular condyle in the rhesus monkey (Macaca mulatta). Am J Anat 1978; 151: 103-18.

12. Simmons DJ, Russell Je, Walker WV, Grazman B, OlOFF C, KAZARIAN L. Growth and maturation of mandibular bone in otherwise totally immobilized rhesus monkeys. Clin Orthod Rel Res 1984; 182: 220-30.

13. Hurme VO, Van Wagenen G. Basic data on the emergence of permanent teeth in the rhesus monkey (Macaca mulatta). Proc Am Phil Soc 1961; 105: 105-40.

14. Cobel-Geard RJ, Carlson DS, Burke RH. Intermaxillary fixation of primates for craniofacial research. J Oral Surg 1979; 36: 562-3.

15. Hinton RS, CARLSON DS. Histological changes in the articular eminence and mandibular fossa during the growth of the rhesus monkey (Macaca mulatta). Am J Anat 1983; 166: $99-116$

16. LudER HU. Growth direction in the mandibular condyle of pre-pubertal and pubertal monkeys (Macaca fascicularis) studied by morphometry and autoradiography. Arch Oral Biol 1987; 32: 239-47.

17. MCNamara JA JR. An experimental study of increased vertical dimension in the growing face. Am J Orthod 1977; 71: 382-95.

18. Carlson DS, Ellis E, Schneiderman ED, Ungerleider J. Experimental models of surgical intervention in the growing face. 1. Cephalometric analysis of the facial growth and relapse. In: MCNAMARA JA JR, ed. Craniofacial growth series. Vol. 12. Effect of surgical intervention in craniofacial growth. Center for Human Growth and Development, University of Michigan, Ann Arbor, 1982; 11-72.

19. Carlson DS, SchneIderman ED. Cephalometric analysis of adaptation after lengthening of the masseter muscle in adult rhesus monkeys. Arch Oral Biol 1983; 28: 62737.

20. Schneiderman ED, Carlson DS. Cephalometric analysis of condylar adaptations to altered mandibular position in adult rhesus monkeys, Macaca mulatta. Arch Oral Biol 1985; 30: 49-54.

21. Rowe TK, Carlson DS. The effect of bite opening appliances on mandibular rotational growth and remodelling in the rhesus monkey, Macaca mulatta. Am J Orthod Dentofac Orthoped 1990; 98: 544-9.

22. Sim YD, Carlson DS, Emrick B. Condylar growth after increased vertical dimension in adult rhesus monkeys. $J$ Dent Res 1991; 70: 519 (only).

23. Woodside DG, Metaxas A, Altuna G. The influence of functional appliance therapy on glenoid fossa remodeling. Am J Orthod 1987; 92: 181-98.

24. Moyers RE. Handbook of orthodontics. 4th ed. Chicago: Year Book Medical Publishers, Inc, 1988; 61.

25. Petrovic AJ, Stutzman J, Oudet C. Control process in the postnatal growth of the condylar cartilage. In: MCNAMARA JA JR, ed. Craniofacial growth series. Vol. 4. Determinants of mandibular form and growth. Center for Human Growth and Development, University of Michigan, Ann Arbor, 1975

26. JoHnSTON LE. The functional matrix hypothesis: reflections in a jaundiced eye. In: MCNAMARA JA JR, ed. Craniofacial growth series. Vol. 6. Factors affecting the growth of the midface. Center for Human Growth and Development, University of Michigan, Ann Arbor, 1976.

27. ENLOW DH. Role of the TMJ in facial growth and development. In: Laskin D, Greenfield W, Gale J, eds. The president's conference on the examination, diagnosis, and management of temporomandibular disorders. Chicago: Am Dent Assoc, 1982.

28. Koski K, Rönning O. Condyle neck periostotomy and the mitotic activity in the condylar tissues of young rats. Swed Dent J 1983; Suppl. 15: 109-13.

29. Glineberg RW, Laskin DM, Blaustein DI. The effects of immobilization on the primate temporomandibular joint: a histologic and histochemical study. J Oral Maxillofac Surg 1982; 40: 3-8.

30. Lydiat DD, Davis LF. The effects on immobilization on the rabbit temporomandibular joint. J Oral Maxillofac Surg 1985; 43: 188-93.

31. IsACSSON G, IsBerg A. Tissue identification of the TMJ disc and disc attachments and related vascularization. $J$ Craniomand Pract 1985; 3: 374-9.

32. Evans EB, Eggers GW, Butler JK. Experimental immobilization and remobilization of rat knee joints. $J$ Bone Joint Surg 1960; 42: 737-41.

33. Finsterbush A, Friedman B. Early changes in immobilized rabbit knee joints: a light and electron microscopic study. Clin Orthop 1973; 92: 305-9.

34. Thaxter TH, Mann RA, Anderson CF. Degeneration of immobilized knee joints in rats. J Bone Joint Surg 1965: 47: $567-71$. 
This document is a scanned copy of a printed document. No warranty is given about the accuracy of the copy. Users should refer to the original published version of the material. 